\title{
LA AUTOBIOGRAFÍA COMO GÉNERO DE FRONTERA: DOS ESCRITORAS MEXICANAS DE CUERPO ENTERO
}

\author{
Claudia L. Gutiérrez Piña \\ Universidad de Guanajuato \\ claudia.gutierrez@ugto.mx
}

Resumen: En la década de 1990 apareció en México la colección de autobiografías De cuerpo entero, con la participación de veintinueve escritores mexicanos. La pluralidad de las propuestas vertidas en sus títulos revela la condición fronteriza que Pozuelo Yvancos ha señalado como característica inherente a la naturaleza de este género. En este artículo se analizan dos de estas propuestas pertenecientes a las escritoras Ethel Krauze y Angelina Muñiz-Huberman, en el marco de su aportación para la autobiografía escrita por mujeres y para la vida del género en el contexto literario mexicano.

Palabras clave: autobiografía, autobiografía escrita por mujeres, autofiguración, Ethel Krauze, Angelina Muñiz-Huberman.

\begin{abstract}
In the decade of 1990 was published in Mexico the collection of autobiographies De cuerpo entero, with the participation of twenty-nine Mexican writers. The plurality of their proposals reveals the border condition that Pozuelo Yvancos has recognized as an inherent characteristic to the nature of this genre. This article analyzes two of these proposals in the autobiographies by Ethel Krauze and Angelina Muñiz-Huberman, in the context of their contribution for women's autobiography and for the life of the genre in the Mexican literary context.
\end{abstract}

Keywords: autobiography, women's autobiography, self-figuration, Ethel Krauze, Angelina Muñiz-Huberman.

DOI: $\underline{\text { htps://doi.org/10.24029/lejana.2017.10.165 }}$

Recibido: el 17 de julio de 2017

Aceptado: el 25 de septiembre de 2017

Publicado: el 4 de noviembre de 2017 
De cuerpo entero es una colección de autobiografías de escritores mexicanos publicada entre 1990 y 1992 por la Dirección de Literatura de la Universidad Nacional Autónoma de México en coedición con Corunda, editorial creada por la escritora Silvia Molina, quien, al lado de Joaquín Armando Chacón y Hernán Lara Zavala, coordinaron esta colección con el objetivo de que su generación "fuera mejor conocida entre el público lector" (Lara Zavala, 1998). El diseño de la colección, que acogió un total de veintinueve escritores, incluye en sus hojas la reproducción de un fragmento del manuscrito, mecanuscrito o pruebas de edición de cada texto y en sus contraportadas, la fotografía del autor. Para el lector mexicano, tanto el diseño como el concepto editorial traen inevitablemente el recuerdo de una serie hermana que sin duda es su antecedente y su modelo. Me refiero a Nuevos escritores mexicanos del siglo XX presentados por sí mismos ${ }^{1}$ publicada tres décadas antes, entre 1966 y 1968, ${ }^{2}$ por iniciativa de Rafael Giménez Siles y Emmanuel Carballo, quienes, en su momento, convocaron a once jóvenes escritores de la época para que escribieran sus autobiografías.

La relación que De cuerpo entero guarda con Nuevos escritores fue señalada por la misma Silvia Molina, quien además vierte algunos comentarios significativos respecto a la escritura de la autobiografía mexicana:

En México, este género [la autobiografía] no se cultiva y creo que la mayoría de las veces, por una falsa modestia; y otras, porque se piensa que las autobiografías las hacen los autores que están viejos, retirados en la soledad de su estudio, entregados ya sólo a recordar su vida y a hablar de su trabajo. En cambio, en otros países, la autobiografía es un género común y corriente, que además goza de buenas ventas.

El primer esfuerzo editorial que se dio a la tarea de publicar este género en nuestro país, como es bien sabido, lo realizó Emmanuel Carballo, cuando le pidió a un grupo de escritores jóvenes de aquella época que escribieran sobre su vida [...].

Yo siempre había tenido la inquietud de las autobiografías [...] Así que pensé en editar una colección que nos presentara de alguna manera a los que están haciendo literatura en nuestro país. Pero escritores de todas las tendencias, de todos los grupos, de todas las edades. (Molina, 1998: 41$)^{3}$

Las palabras de la escritora y editora resultan reveladoras en varios sentidos. Aluden, por una parte, a la lectura generalizada respecto a la ausencia de la tradición autobiográfica en la literatura mexicana, visión que es necesario discutir a la luz de una revisión sistemática de la vida de este género en México, ${ }^{4}$ problemática que, aunque no es el objetivo central de este escrito, es

\footnotetext{
${ }^{1}$ Desde este momento, por economía, me referiré a esta serie como Nuevos escritores.

${ }^{2}$ El diseño de Nuevos escritores incluía en la cara interior de la portada la reproducción del manuscrito del texto y en su contraportada la fotografía del autor, con una breve ficha vital y reproducción de su firma.

${ }^{3}$ En el mismo tenor, dentro de la misma colección, María Luisa Mendoza advierte también la relación entre la serie y la colección, al abrir su autobiografía con la siguiente alusión: "Debo confesar que hubo una serie de autobiografías en hilo témpore publicadas en México y contadoras de las breves vidas de sus autores jóvenes, y de algunas recuerdo pasajes entremezclados que tal vez he inventado con el tiempo y no quiero rectificar; eran magníficas, literarias y terribles, un enorme ejercicio de invención y de vanidad que deberíase [sic] repetir cada treinta años por lo menos, y estos intentos que empiezo empujan la puerta entreabierta" (1991: 10).

${ }^{4}$ Si bien aún no existe este trabajo de estudio sistemático de la autobiografía en México, sobre todo en las últimas décadas se han generado algunos acercamientos. El primer ejercicio de revisión de la tradición autobiográfica en México de la que tengo conocimiento pertenece a la labor de Raymundo Ramos con su antología Memorias y
} 
importante recuperar para ubicar el lugar en que se inserta el proyecto de la colección De cuerpo entero.

La observación de la ausencia de tradición autobiográfica en México permeó, por ejemplo, la visión de Jorge Ruffinelli, quien advirtió hace unas décadas acerca del "hueco" en la escritura de autobiografías no solo en México, sino en Hispanoamérica: "ni a los cuarenta ni a los sesenta ni a otra edad el escritor hispanoamericano por lo general acomete esta aventura, y el género se convierte en un hueco dentro de las prácticas de escritura si comparamos nuestra tradición con otras, la anglosajona por ejemplo" (1986: 513). Y agrega "así como no se han escrito en América Latina autobiografías en un sentido estricto, es también probable que nunca se escriban" (1986: 514). La mirada del crítico, signada por un poco afortunado gesto comparativo, obvia lo que en otro momento señaló Sylvia Molloy, al reconocer que en Hispanoamérica hay una dinámica de recepción en la que las escrituras autobiográficas han sido contextualizadas en función de "los discursos hegemónicos de cada época, se las declara historia o ficción, y rara vez se les adjudica un espacio propio" (1996: 12). En el mismo tenor se encuentran los comentarios de Bettina Pacheco Oropeza, quien señala: "La situación de la autobiografía en Latinoamérica estuvo marcada durante bastante tiempo por la creencia de que no existe una tradición autobiográfica similar a la de países como Inglaterra e Italia, de arraigada tradición memorialista, cuando lo que en verdad ha ocurrido es que han fallado, tanto la recepción como la crítica, al no otorgarle un espacio propio más allá de la historia o la ficción" (2007: 531). De tal forma, en el posible trazado de la dinámica del género no pueden dejar de considerarse las condiciones históricas, sociales, culturales y editoriales de las que participa el escritor.

Para el caso que me ocupa, resulta pertinente recordar la transición del ambiente político, social y cultural de la segunda mitad del siglo XX, la cual contribuyó para la profesionalización de la actividad del escritor, que iniciara en la década de 1960, proceso en el que la figura de Carballo fue clave. Así lo advierte el propio editor y crítico, al recoger en su Diario público la experiencia de su participación en el ambiente cultural mexicano de la época, atribuyéndose como uno de sus logros "convertir al escritor mexicano en noticia y a sus obras en mercancías acordes con el sistema capitalista [...]; practicar la política de puertas abiertas con todo aquel que tuviese talento y lo aplicara a partir de sus primeras obras" (Carballo, 2015: 16). Esta labor se entreteje con el crecimiento que tuvo la industria editorial en esos años: con el antecedente de la creación del Fondo de Cultura Económica (1934), surgieron también en la década de 1960 Era y Joaquín Mortiz, dos de las casas editoriales más importante de la época. A esto se suma la consolidación

autobiografías de escritores mexicanos (1967), trabajo donde recoge ejemplos de textos autobiográficos que transitan desde el siglo XIX al XX, con muestras de la escritura de Fray Servando Teresa de Mier, José Guridi y Alcocer, Guillermo Prieto, Federico Gamboa, Victoriano Salado Álvarez, José Juan Tablada, Enrique González Martínez, José Vasconcelos y Jaime Torres Bodet. El trabajo de Ramos está determinado por los límites propios de su labor de antólogo, sin embargo, puede considerarse como un acercamiento seminal, al que se suman aportaciones posteriores, como el texto de Magdalena Maiz, (Entre)textos: perfil de la autobiografía moderna en México (1992), los trabajos de Richard D. Woods, Mexican Autobiography/Autobiografia mexicana (1988), "Mexican Autobiography: An Essay and Annotated Bibliography" (1994) y "Profile of Women's Autobiography in México" (1994), así como el trabajo reciente de Luz América Viveros, El surgimiento del espacio autobiográfico en México. Impresiones y recuerdos (1893), de Federico Gamboa (2015). 
de instituciones culturales que promovieron la profesionalización del escritor: la creación del Centro Mexicano de Escritores (1951), la Coordinación de Difusión Cultural de la Universidad Nacional Autónoma de México (1947) y la fundación de La Casa del Lago (1959). Precisamente es como producto de este contexto que surge la serie Nuevos escritores, según he tratado ya en otro lugar (Gutiérrez Piña, 2017), tendencia a la que años después se suma la colección $D e$ cuerpo entero. Para la década de 1990, cuando surge esta segunda colección, la vida política, social y cultural mexicana había ya pasado por el largo proceso del proyecto modernizador de los gobiernos posrevolucionarios — con sus logros y estridentes fracasos - cuya huella se advierte en una infraestructura apabullante de institucionalización del campo intelectual con la creación del Fondo Nacional para la Cultura y las Artes (FONCA) en 1989, el Consejo Nacional para la Cultura y las Artes (Conaculta) en 1992 y el Sistema Nacional de Creadores de Arte en 1993.

En este contexto, podemos hablar de que ambos proyectos - el de Carballo y el de Molina - se enmarcan en un ambiente cultural donde el trabajo de editores e instituciones evidencias sus alcances como legitimadores de la producción artística que vieron en la escritura autobiográfica una estrategia de difusión de las figuras del escritor. Los resultados, sin embargo, fueron muy distintos. Mientras Nuevos escritores es, al día de hoy, un referente memorable para lectores y críticos de la obra de los escritores pertenecientes a la Generación de Medio Siglo, De cuerpo entero tuvo un impacto menor $\mathrm{y}$, a la fecha, la recuperación de esta serie es prácticamente nula. $^{5}$

Al margen de estas diferencias de la recepción, que necesitarían de un espacio propio para ser desarrolladas, me importa resaltar que estos dos proyectos editoriales han condicionado el modo en que los escritores mexicanos se enfrentan con la escritura de la autobiografía y que han definido en gran parte la dinámica de la vida del género en las últimas décadas: en primer lugar, es una escritura "por encargo", que responde al mencionado interés editorial de promoción de las figuras de escritor. Después está la brevedad como signo, ya que la extensión de los textos, por criterio editorial, no supera las 60 cuartillas, cuestión significativa si se considera la extensión general de las autobiografías tradicionales. Y finalmente, han dado cabida a lo que propongo leer como una apuesta por la variación de formulaciones, modos de ejecución, o bien — como propone Pozuelo Yvancos- "estilos" del género que se desatan en tanto "opciones que un autobiógrafo tiene en el interior de un género para ejecutar su creación" (Pozuelo Yvancos, 2006: 109).

Algo que permitió poner en evidencia tanto Nuevos escritores como De cuerpo entero es la complejidad de la autobiografía por las estrategias escriturales que es posible poner en funcionamiento en el gesto autofigurativo, condición que, a su vez, ha propiciado las grandes

\footnotetext{
${ }^{5}$ Una posible explicación es dada por la misma Silvia Molina, quien señala en entrevista: "siento que esa colección tuvo un problema de principio. La UNAM se queda con un número determinado de ejemplares que regala a los críticos, a la gente del medio, a los profesores, que son la posible compra en una librería. Pero no se le da mucha promoción. Son libros que llaman la atención. En muchas universidades los adquieren para estudiar la intimidad del escritor, pero hay el problema de la distribución" (Estrada, 1994). La declaración de Molina pone sobre la mesa una de las problemáticas inherentes a la dinámica de profesionalización del escritor en México — que puede leerse también como una tendencia general- ya que las instituciones, entre ellas también la academia, hace en muchos casos de su trabajo una producción que queda a puerta cerrada entre la misma comunidad académica.
} 
discusiones teóricas sobre la caracterización del género, particularmente en los que concierne a los lindes entre el estatuto no ficcional y los recursos ficcionales implicados en su escritura, elementos que han sido, en mucho, puntos de partida para la mayoría de las reflexiones. Al respecto, me parece que una de las discusiones más afortunadas corresponde al trabajo de Pozuelo Yvancos, quien retoma la división verdad/ficción que ha signado las dos principales perspectivas en las reflexiones teóricas, para conciliarlas al reconocer una condición "fronteriza" como consustancial a la autobiografía. ${ }^{6}$

La naturaleza fronteriza que propone el teórico español distingue la fisonomía problemática del género a la vez que la resuelve. Por una parte, la problematiza porque recala en "la enorme dispersión de variedad de las formas que adopta este género" (Pozuelo Yvancos, 2006: 19), pero también la resuelve al someter a cuestionamiento lo que plantea como "un error de óptica" si se piensa la noción de género en términos de una forma fija. En palabras de Pozuelo Yvancos: "La mayor parte de los problemas que aquejan al estatuto del género autobiográfico derivan de un error de óptica: el que adviene cuando se pretende reglamentar un género en términos abstractos o teóricos, sin advertir que todas las cuestiones de género implican horizontes normativos de naturaleza histórica y cultural" (2006: 21).

Esta caracterización propuesta para la autobiografía permite imbricar las condicionantes de la dinámica del género en la que subyacen los elementos pragmáticos y retóricos, sin que se excluyan uno al otro. Con ello es posible no perder de vista que la autobiografía como género "no es una opción o modelo abstracto, sino una realización histórica concreta [...] con esa «angustia de la influencia» que rige los procesos de originalidad literaria y que ha proporcionado a la historia de cada género una fisonomía por fortuna convulsa, dinámica, histórica en suma" (Pozuelo Yvancos, 2006: 106), perspectiva que es particularmente útil para pensar el caso de la autobiografía mexicana.

Para el caso de la colección De cuerpo entero, esta dispone de un marco de ejecución que le signa, no en los términos de modelo abstracto, como refiere Pozuelo Yvancos, sino como realización histórica en una dinámica concreta que da continuidad a un modelo más bien de tipo editorial. Retomo nuevamente las palabras de Molina con las que abrí este texto, para advertir que en el reconocimiento del proyecto de Siles y Carballo como el "esfuerzo editorial" que dio espacio a la escritura de la autobiografía en México, el proyecto de Molina instaura su continuidad y transformación. Nuevos escritores funge como modelo para la colección De cuerpo entero en el sentido que hace del género un espacio para el "posicionamiento" de escritores en el escenario literario, si bien la apuesta de Molina, retomando sus declaraciones, fue abrir el abanico hacia "escritores de todas las tendencias, de todos los grupos, de todas las edades", palabras que seguramente aluden al bien conocido sectarismo del que fue acusado el grupo vinculado Carballo

\footnotetext{
${ }^{6}$ En palabras de Pozuelo Yvancos: “desde su aparición en las Confesiones de San Agustín hasta sus formulaciones más recientes, [la autobiografía] nunca ha dejado de jugar con su propio estatuto dual, en el límite entre la construcción de una identidad, que tiene mucho de invención, y la relación de unos hechos que se presentan y testimonian como reales" (2006: 17).
} 
y que se trasluce en la lista de los escritores que fueron convocados por este para participar en Nuevos escritores. ${ }^{7}$

En efecto, De cuerpo entero representa un mosaico con mayor pluralidad, como puede advertirse simplemente en el número de escritores convocados, entre los que se encuentran narradores, dramaturgos, ensayistas y poetas de diferentes generaciones, nacidos entre las décadas de 1920 a $1950 .{ }^{8}$ Además, De cuerpo entero subsana la ausencia de escritoras en el mosaico de la generación de escritores que el proyecto coordinado por Carballo perfiló, sin duda una de las omisiones más discutibles en términos de la representatividad que pretendía. ${ }^{9}$

En este caso, me interesa detenerme precisamente en la aportación que representa para la literatura mexicana la participación de las escritoras involucradas en el proyecto de Silvia Molina, particularmente porque en una revisión general la de autobiográfica mexicana las escritoras cuentan con poca representatividad (Woods, 1994). De la colección participan María Luisa Mendoza (1930), Angelina Muñiz-Huberman (1936), Aline Petterson (1938), Beatriz Espejo (1939), Brianda Domecq (1942), María Luisa Puga (1944-2004) y Ethel Krauze (1954), escritoras todas ellas que comienzan a publicar en la década de 1970 y se encuentran en el marco de lo que en algunos espacios se ha denominado como el boom femenino (Reisz, 1990) ${ }^{10}$ o que bien da continuidad a lo que Aralia López distingue como la "aparición consistente [de las mujeres] como nuevos sujetos sociales en la literatura" (1993: 664). ${ }^{11}$

En particular, para la vida del género de la autobiografía mexicana, la participación de

\footnotetext{
${ }^{7}$ Un tratamiento puntual sobre la serie Nuevos escritores mexicanos del siglo XX presentados por sí mismos y los aspectos a que aludo han sido desarrollados en el artículo "La precocidad en la autobiografía mexicana: un proyecto editorial. Nuevos escritores mexicanos del siglo XX presentados por sí mismos" (Gutiérrez Piña, 2017).

${ }^{8}$ El total de escritores participantes son: Humberto Guzmán, Federico Campbell, Ethel Krauze, Aline Petterson, María Luisa Puga, Rafael Ramírez Heredia, Víctor Hugo Rascón Banda, Bernardo Ruiz, Ignacio Solares, Gerardo de la Torre, Luis Zapata, Alejandro Sandoval, Eugenio Aguirre, Héctor Azar, Roberto Bravo, Emmanuel Carballo, Marco Aurelio Carballo, Fernando Curiel, Brianda Domecq, Beatriz Espejo, Rafael Gaona, María Luisa Mendoza, Angelina Muñiz-Huberman, Federico Patán, Joaquín Armando Chacón, Vicente Leñero, Jorge Portilla, Alberto Ruiz Sánchez y Paco Ignacio Taibo II.

${ }^{9}$ El propósito editorial, impreso en la primera página de los 11 títulos publicados de la serie Nuevos escritores señalaba la intención de mostrar un perfil generacional representativo de la época: "La presente colección se inspira en el propósito de dar a conocer en páginas autobiográficas la fuerte personalidad de los jóvenes escritores mexicanos del momento, para que el lector de habla hispana, impresionado por la calidad humana y el inteligente laborar de estos nuevos valores literarios, acuda desde luego a conocerlos en sus obras".

${ }^{10}$ Al respecto, como bien señala Aralia López, una de las investigadoras que más ha aportado en el estudio de la literatura mexicana escrita por mujeres, existe una suerte de "recelo" en el estudio de lo que se conoce como boom femenino, por la gran cantidad de títulos que surgieron en la década de 1980 y el éxito comercial particularmente de obras como Arráncame la vida (1985) de Ángeles Mastreta, y Como agua para chocolate (1989) de Laura Esquivel: "Esta producción hace pensar a los más en un fenómeno comercial y no tanto en una creación de buena ley. Sin embargo, en esto influyen los prejuicios sexistas y el rechazo o no comprensión de corrientes críticas actuales, entre ellas la culturalista y la feminista. Las mismas escritoras participan de estos prejuicios e incluso, la crítica académica parece tener dificultades para tratar, en general, las no canónicas producciones de este periodo" (López, 1993: 659660).

${ }^{11}$ Este movimiento en la dinámica literaria mexicana tiene un eje reconocible entre las décadas de 1950 y 1960: "Las narradoras Elena Poniatowska con Lilus Kikus (1954); Rosario Castellanos (1925-1974) con Balún-Canán (1957), Ciudad real (1960) y Oficio de tinieblas (1962); Luisa Josefina Hernández con El lugar donde crece la hierba (1959); y Elena Garro con Los recuerdos del porvenir (1963) y La semana de colores (1964), son los nombres y obras pioneros de la narrativa mexicana contemporánea escrita por mujeres, la misma que tiene su «boom» en los ochenta" (López, 1993: 664).
} 
este grupo de escritoras es significativa porque permite pensar la vinculación del género con el "campo intelectual" que la misma Aralia López pone sobre la mesa al pensar en esta "aparición consistente" de las escritoras en la literatura mexicana, es decir, vinculada con "la constitución de un campo intelectual [que] supone agentes e instituciones que proveen los criterios de legitimidad cultural" (López, 1993: 659), como he señalado antes. En el caso de la colección De cuerpo entero, como lo fue para Nuevos escritores en su momento, los proyectos editoriales fungen precisamente como uno de esos "agentes" de legitimación en el que, sin embargo, también se dirime la ejecución del talento creativo.

\section{La potencia multiforme de la autobiografía}

La mencionada cualidad fronteriza de la autobiografía, aunque ha sido leída de inicio en términos de la implicación de la configuración literaria de una identidad y su relación con unos hechos que se testimonian como reales, le otorga también un carácter multiforme potencial, como puede observarse en los títulos que conforman De cuerpo entero, en los que se articulan formulaciones plurales de la autobiografía, auspiciadas en dicha naturaleza fronteriza del género.

No resulta extraño que uno de los recursos utilizados por algunas de las escritoras aludidas sean estrategias narrativas que se deslizan entre distintas modulaciones discursivas como suma de una voluntad estética que configura el universo del relato con los recursos propios del escritor como artífice en el sentido más clásico del término. No es extraño por ello que en las distintas formulaciones del género subyazca un tejido que deliberadamente tiende puentes con estrategias del hacer creador y la tradición literaria. Es en este sentido que De cuerpo entero representa una suerte de abanico de diferentes estilos en que esa potencia multiforme se concretiza. Valga para los fines de este artículo reconocer algunas de sus posibilidades en las autobiografías de dos de las escritoras mexicanas involucradas: la dualidad como arquitectura de la textualidad en analogía con la de la identidad, para el caso de Ethel Krauze, y la fragmentariedad pluriforme, en el de Angelina Muñiz Huberman.

\section{La identidad como dualidad: Ethel Krauze}

Ethel Krauze configura su autobiografía tomando como punto nodal el sentido de la construcción de una identidad condicionada por la fusión de una biculturalidad. Krauze pertenece a la comunidad judeo-mexicana que se consolida en México particularmente en el siglo XX como producto de la emigración masiva desde países europeos hacia tierras americanas, producto de las grandes guerras. Como señala Shulamit Goldsmit, en el caso mexicano se combinaron dos condiciones: los escenarios de expulsión en los países de origen orientales y europeos, así como la política posrevolucionaria de puertas abiertas a la inmigración:

Mientras en los países de origen de los emigrantes se exacerbaban las condiciones expulsoras [...] las propuestas mexicanas actuaron como una llamada, lo que propició que entre 1920 y 1929 México recibiera continuas oleadas de jóvenes judíos en su mayoría del sexo masculino. En la década siguiente llegaron novias, esposas, hermanas, así como audaces mujeres que arribaron solas a tierras americanas. (2010: 121$)$ 
Ethel Krauze pertenece a la tercera generación de una de estas familias de emigrantes judíos. Su abuelo paterno, de origen ucraniano, resistió la revolución rusa y escapó de la persecución de los cosacos embarcándose hacia el puerto de Veracruz. Mujer e hijos lo acompañarían dos años después, como sucedió con muchas familias judías, según relata Goldsmit.

Las vicisitudes que enfrentó la familia Kolteniuk abren el relato de Ethel Krauze, en la tradicional fórmula de la construcción de la genealogía y el mito de los orígenes. La figura del abuelo Piotr es el punto de partida, como enclave de uno de los extremos de la simbólica dual que fungirán como los hilos que terminan por tejer la identidad de la autobiógrafa perfilada en el título del relato: Entre la cruz y la estrella.

En la imagen de Piotr se conjugan la Historia y las historias personales, signadas por la estrella de David, como símbolo articulador de identidad:

En la nevada Ucrania del zar Nicolai, Kalínovka era un punto en los mapas chicos rodeado de trigales. Los Kolteniuk tuvieron cinco hijos. Piotr siguió el oficio de su padre, que eran dos: rezar y vender telas. Aunque el segundo le dio de comer más mal que bien hasta su apacible muerte en la colonia Condesa de la ciudad de México, el primero lo dotaba de un olor a cera bendecida, a vino del profeta Elías en copa labrada, a cuerno que abre los oídos a dios el día del perdón, palio para las bodas del rey David. De estirpe cohen, principesca entre judíos, podría hacer las veces de rabino, y en cualquier ceremonia su presencia imponía solemnidad y suspiros al cielo. (Krauze, 1990: 9$)^{12}$

La figura del abuelo encarna en estas breves líneas las claves del relato del judaísmo que condicionan la historia personal de la autobiógrafa: en la referencia histórica, por medio del zar Nicolai, se concentra el trasfondo de la caída del régimen zarista y la revolución rusa que diera pie a los conflictos intestinos que derivaron en la persecución y desataron la salida de muchos judíos para "hacer la América". En las marcas geográficas (el movimiento Kalínovka - Ciudad de México) queda trazada la ruta de la emigración. Mientras que en las referencias a los símbolos de la ritualidad judaica se condensa la tradición traída consigo. Todos estos elementos representan de alguna forma el pasado compartido por la comunidad judeo-mexicana a la que pertenece la escritora y que será desatado en los primeros apartados, al completar la historia particular de las dos familias en que enraíza su árbol genealógico: los Kolteniuk y los Krauze. Para ello, la narradora recupera el relato de las mujeres de su familia, sus abuelas, con la imbricación de diálogos, más cercanos a una estructura novelesca, en los que se acentúa la estilización de una oralidad producto de la hibridez lingüística, particularmente en la figura de la abuela Ana, cuya voz mezcla las palabras del yiddish con el español en una alternancia de códigos, como se advierte en el siguiente diálogo: "Pero no hija, ¿ya ves? No pudía quitar hijo a tu zeide iy primer hijo! No, veis mier, hubiera matado a mí, y tú hija, no hubieras nacido... O quén sabe, a lo mejor foiras hoy francesita" (13). ${ }^{13}$

\footnotetext{
${ }^{12}$ Todas las citas al texto corresponden a esta edición. En lo que sigue consigno solo el número de página.

${ }^{13} \mathrm{Al}$ inicio de la autobiografía de Krauze, el lector puede fácilmente identificar un estilo discursivo que hace oscilar la narratividad con la inserción de los diálogos de la abuela, para después dar paso a otras voces: los abuelos maternos, Jaya y Shíe, hasta llegar a sus padres: Reizel y Lázar, cada vez con menor marca de la alternancia de
} 
Importa subrayar esta característica, inicialmente acentuada en el relato autobiográfico desde el nivel lingüístico, porque la condición de dualidad e hibridez, como he anticipado, terminará por ser la dinámica constitutiva y totalizante de la estructura del relato $\mathrm{y}$, por lo tanto, de la personalidad construida de la autobiógrafa. Entre la cruz y la estrella se articula en el juego de dualidades que interactúan en términos de una textualidad que termina por operar como analogía de la identidad construida; es decir, como producto de la interacción de elementos identitarios plurales, o bien, como ha señalado Guadalupe Cortina, para dar cabida a "la manifestación de una subjetividad interceptada por varias posicionalidades, que se configuran textualmente" (2002: 92). A las "posicionalidades" que reconoce Cortina cabe agregarles el adjetivo de duales, según propongo. Una de ellas ya la he anotado - la lingüística, presente en la estilización de la voz de la abuela-, a la que se suman otras: la de la memoria escrita, ya que, según se advierte en una nota a pie del texto, para reconstruir la historia de su pasado familiar, la autora retoma "un largo relato autobiográfico de [su] madre" (22), lo que supone reconocer el discurso como un tejido de doble hebra, donde la memoria escrita de la madre se entrecruza con la memoria escrita de la hija para la configuración de la genealogía, cuyo cierre adviene con el nacimiento de la narradora: "Yo vine el 14 de junio de 1954. Una bola de ojos capulines y mechas negras" (34). A partir de ese momento, la disposición de la autobiografía muta hacia la forma del relato de infancia, como segunda base en la formación del mito personal.

Así como se hiciera en la primera parte con la figura del abuelo Piotr, en tanto representante de una vena cultural en la identidad judía de la autobiógrafa, en el relato de infancia aparece una identidad que funge como el hilo estructurante de la segunda construcción simbólica definida en el título: la cruz. Aunque inicialmente se puede pensar solo en la implicación religiosa, la cruz se presenta más bien como una simbólica cultural e idiosincrática de la cultura mexicana encarnada en la figura de María, la nana de la narradora, india molendera que hace las veces de matriarca en la casa familiar.

La dinámica de esta segunda sección confirma la estructura de dualidades. Dos de estas resultan las más significativas: la figura materna articulada en el contrapunto Rosa ${ }^{14}$ - María, con sus correlativos espacios: la casa principal, que alberga la figura de la madre y "la casa de adentro", donde María instaura su pequeño feudo. Rosa, representa una figura mentora en lo que concierne a la cultura occidental. Estudiante de filosofía, acerca a sus hijos al pensamiento platónico y a la poesía de García Lorca en las sobremesas, que son también los espacios de descanso para su quehacer intelectual implicado en la tarea de una tesis doctoral, que al parecer consume los años de infancia de la narradora. Mientras que María, la nana, representa la guía y el asidero en el universo de lo cotidiano, poblado de los olores y sabores de la cocina, el juego, los relatos populares, el culto al símbolo religioso mexicano más acendrado, la virgen de Guadalupe, los mercados, las historietas.

En la reconstrucción de la doble casa familiar como lugar recuperado por la memoria de la autobiógrafa, se "espacializa" la fusión de tradiciones, valores religiosos, éticos e históricos, el

códigos, condición que muestra discursivamente el movimiento de apropiación del español en el seno familiar conforme avanza el dibujo de la línea generacional.

${ }^{14}$ Castellanización de su nombre judío Reizel. 
lenguaje, los usos y costumbres, la gastronomía y la idiosincrasia que sostienen la identidad de la escritora: "Aún no me explico cómo cabíamos tantas gentes en esa doble casa donde campeaba el yiddish tanto como el náhuatl, los arenques en salmuera con el mole de olla, los pepinos agrios como los chiles en vinagre, los candelabros y el molcajete, el tálit y el rebozo, el kadish y «Las mañanitas», el peisaj y la Navidad, Jehová y la Virgen de Guadalupe" (42).

La condición de duplicidad, evidenciada en la cita anterior, deriva en un breve tercer capítulo, con la reconstrucción del recuerdo de la vida escolar a la que se enfrenta la narradora. Espacio que se presenta como contexto condicionante de la adquisición de conciencia del sujeto narrado frente a la realidad o, desde una perspectiva simbólica, como la pérdida del espacio edénico, paraíso perdido de la infancia, como señalan las palabras de la narradora: "El quiebre de todo ese mundo comenzó el día en que me llevaron a la escuela" (47). Este quiebre deriva por el reconocimiento de la dualidad que, vivida con plena "naturalidad" en la casa familiar, al ser enfrentada con la dinámica del mundo de "afuera", se convierte en problemática.

En el contacto con el Colegio Israelita de México, ${ }^{15}$ la narradora articula una crítica a la "psicopalogía" creada a favor de la conservación y defensa de la cultura judía en las aulas del Colegio. Las divisiones raciales, nunca vividas en casa, se convierten en una dinámica irónicamente institucionalizada de la diferencia que, en palabras de la narradora, consistía en la siguiente tesis:

PRIMERO, eres un ser superior porque vienes del Dios verdadero; los demás, todo le resto del mundo, los goyim, son imbéciles. Sobre todo los mexicanos, que además son seiguets, shkotz y dinstn, o sea, pelados, nacos, criadas y esclavos. Creen en Jesucristo ino pronuncies ese nombre asqueroso!, es un goy, católico, farsante y naco. No te mezcles, no te ensucies; y SEGUNDO, todo el mundo te persigue. Te quieren matar en hornos y crematorios y enterrar viva y hacerte jabón y pantalla de lámpara. (49)

Krauze, en la recuperación y bosquejo del relato de infancia, realiza una crítica, en apariencia inocente - por estar escenificada en la natural crueldad del mundo infantil—, al sectarismo y elitismo inculcados en boga de la defensa de una herencia de identidad que paradójicamente replica las bases del sufrimiento propio en la imagen de una estructura social en microescala, donde se ponen en uso "las torturas hitlerianas que los niños habían aprendido con gran destreza" contra los diferentes, los menores, los niños mexicanos pobres que las políticas de la Secretaría de Educación Pública obligaba al Colegio a recibir, así como a la permisividad del contexto mexicano, cómplice e incluso promotor de esta dinámica social.

Las últimas líneas de la autobiografía y su tercer apartado en general funcionan como estructura que imbrica textualmente la condición de dualidad que subyace en la construcción de la identidad propia, en una dinámica que apunta, muy seguramente, a la lógica simbólica de la

\footnotetext{
${ }^{15}$ Fundado en 1924 por la comunidad judía en la cual se cubre una educación judía tradicionalista y laica: “en el Colegio Israelita de México, se cumplían, desde el kinder hasta el nivel medio superior, los programas requeridos por la Secretaria de Educación Pública, a la vez que se enseñaba historia del pueblo judío, gramática y literatura idish (en aquel entonces la lengua centralizadora de los ashkenazitas del mundo entero). Los planes escolares incluían el estudio de la Toráh dentro de un carácter estrictamente laico. Puede afirmarse que en esas aulas se concretaron las bases para la identidad judeo-mexicana de gran parte de la niñez y juventud ashkenazita" (Goldsmit, 2010: 110-111).
} 
síntesis. No es extraño que la dualidad operante tanto en la estructura textual como en la configuración de la identidad autobiográfica confiera a este tercer capítulo el carácter de unificación simbólica en el imaginario de la niña, cuando es capaz de conferirle un sentido personal, como aprendizaje individualizado de conciliación interior:

En las clases de español nos enseñaban que veníamos de los indios [...] y que el padre Hidalgo nos había liberado. Pero en las clases de yiddish nos decían que veníamos del padre Abraham y que Moisés nos había liberado llevándonos por el desierto. En las clases de ciencias naturales nos decían que veníamos del mono; en la de historia hebrea, que de Adán y Eva en el paraíso. De modo que en mi cabeza Adán era un mono que hacía ídolos de barro con rasgos olmecas y se los vendía a Moisés, que era un indio guerrero en el paraíso, que era un desierto donde el padre Hidalgo daba el grito de Independencia con la bandera de la virgen Lupita, que era Eva convertida en chimpancé, blandiendo la estrella de David.

Y aquí, en realidad, comienza mi historia (57).

La conciliación por supuesto es lúdica, filtrada por la mirada de la personalidad en ciernes que se articula en el relato de infancia. Sin embargo, subyace en la recuperación del pasado — siempre signada por el presente de la escritura autobiográfica - una suerte de trasluz por el que se filtra la identidad adulta de la narradora. La figura de Krauze se ha caracterizado en las letras mexicanas por el acento que ha dado a la feminidad en su literatura, desde una mirada que la problematiza en términos de diálogo con el otro o lo otro: "El tema de la mujer que lucha entre dos aguas, la imagen antigua y la imagen nueva de ser mujer y que se abre paso es también algo que me apasiona y, diría, que permea toda la obra que he escrito" (Minardi, 1994: 71). Me importa resaltar, antes que la inmediata y muy reiterada lectura de la feminidad en la literatura de Krauze, la estructura dual que la alienta y que se presenta en su autobiografía como el principio que signa la mirada de la autora. Dualidades que operan en todos los niveles: cultural, histórico, social, psicológico. Entre la cruz y la estrella da forma a esta estructura y otorga sentido a la rejilla desde la que se filtra la construcción del yo y el mundo.

\section{El fragmento y la variación como poética de la identidad: Angelina Muñiz-Huberman}

Angelina Muñiz-Huberman, quien comparte con Ethel Krauze la vena de la herencia judía en su historia familiar, se instala en uno de los grandes tópicos de la literatura en general y de la escritura autobiográfica en particular, para configurar la textualidad representativa de su identidad: el exilio.

El tema del exilio abunda en la literatura hispanoamericana y, en la producida en México, hay una importante marca de doble movimiento en el siglo Xx: escritores mexicanos que escribieron fuera del país a raíz del conflicto revolucionario y escritores españoles que escribieron desde México en el marco de la Guerra Civil Española. Angelina Muñiz-Huberman se encuentra, sin embargo, un paso más adelante, porque el exilio toca su experiencia personal como herencia. Esta diferenciación es importante, porque mientras el escritor exiliado confiere en su literatura la implicación nostálgica de un pasado vivido que "se ve como irrecuperable, una patria inasible en el tiempo y en el espacio que sólo se rescata a través de la detallada recreación de la escritura" (Molloy, 1996: 118), para la comunidad hispanomexicana, como se denomina a 
los hijos de exiliados españoles, este pasado se crea —no se recupera,$-{ }^{16}$ se inventa a modo de un mito del origen, como perfila una de las primeras declaraciones de la escritora en su autobiografía: "a veces pienso que el exilio es recrear el paraíso perdido" (Muñiz-Huberman, 1991: 15). ${ }^{17}$ Mirada que se confirma en su obra narrativa, particularmente en Morada interior (1972), donde describe a los niños hispanomexicanos de su generación:

Vivieron al aire, sin tierra en la que apoyar los pies. Se les habló mucho — excesivamente— de lo que era España y se les prometió el regreso. Hubieran podido hacer otra cruzada y recuperar la Santa República. Pero como en el aire no se puede caminar, parecían marionetas de hilos desgastados que se retorcían sin sentido queriendo inventar una historia que nunca se habría de escribir. Porque eso era lo más lamentable, querían representar una historia que no existía para ellos (Muñiz-Huberman, 1972: 108)

Nacida en Hyères, Francia en 1936, Angelina Muñiz-Huberman no tuvo oportunidad de conocer España, pues el arranque de la Guerra Civil le impidió a su familia volver de Francia, y posteriormente iniciaría el éxodo que les hizo llegar a México, después de pasar una temporada en Cuba, cuando Angelina contaba con seis años. Esta condición de desplazamiento y exilio es ponderada desde el inicio de su autobiografía como su principal signo:

La marca del exilio nunca ha podido abandonarme. Ese ir de país en país creó mi propia morada interior. Fui educada en el tráfago de los espacios [...]

Si bien el exilio es obsesivo, tampoco se me convirtió en una carga negativa. Me acompaña y me acompañará siempre. Es tan parte mía que ya no se me desprende, a la manera de miembro del cuerpo. Pero no me abruma, ni provoca mis lamentos, ni me paraliza. Antes bien, todo lo contrario. Se me ha encarnado en nuevas formas, en nuevos rumbos, en grandes espacios abiertos, en carencia de límites y fronteras. En libertad y hasta en anarquía. (10-11, el énfasis es mío)

El tema del exilio es quizá uno de los más tratados por la crítica de la escritora como la marca de su poética personal, al lado de otra obsesión que le complementa: la intertextualidad. En la autobiografía titulada El juego de escribir, las implicaciones de estas dos características participan de la dinámica configurativa de la subjetividad en un tejido que las confirma, desde un estilo fragmentario que potencia descentramientos y transformaciones. El énfasis otorgado al exilio en estas líneas, bajo la forma de una fuerza potenciadora, en la referencia a la "carencia de límites y fronteras", es el sentido otorgado en la literatura de Muñiz-Huberman, el cual encuentra en la autobiografía también un estilo de textualidad que le replica.

Conformada por trece fragmentos, la autobiografía se construye en un juego que imbrica

\footnotetext{
${ }^{16}$ Al respecto, Eduardo Mateo señala: "Los escritores hispanomexicanos no fueron actores de las causas pero sí compartieron con sus padres el efecto: el hecho del exilio-destierro, aunque les vino impuesto, fue, en general, bien aceptado [...]. El suyo fue un exilio heredado con todas las consecuencias negativas que tiene esa realidad. Hay críticos que separan a este grupo en otros tres grupos generacionales. A mi parecer excesiva atomización, si se sigue por ese camino cada individuo formará su propio grupo. Vale diferenciar a aquellos que en su llegada contaban con recuerdos españoles claros (los del grupo de Presencia) y los que no traían sino recuerdos evocados por las conversaciones de sus mayores (los de Clavileño y Segrel, junto con los que vinieron en pañales). Lo más curioso, misterioso, incomprensible e indescifrable es que cuanto más jóvenes eran en el momento de la llegada, más memoriosos han resultado ser. Es el caso Muñiz-Huberman" (2014: 38).

${ }^{17}$ Todas las citas al texto corresponden a esta edición. En lo que sigue consigno solo el número de página.
} 
la forma netamente narrativa con registros que decantan hacia la prosa ensayística e incluso hacia una suerte de "autocrítica literaria", en la que el trayecto vital de la escritora termina prácticamente absorbido por la inserción de citas de algunos fragmentos de su obra poética ("Reconciliación", "Erótica"), fragmentos de una conferencia, marcas de los contenidos autobiográficos filtrados en sus obras con comentarios puntuales como "En unos de mis relatos, «Retrospección» me refiero a ello" o "En unos de mis libros en prensa, Castillos en la tierra, describo esta etapa" (24), así como la notación de títulos, espacios, fechas de publicación, premios recibidos, etc., que dotan por momentos al texto de un tono mucho más académico que intimista.

Esta característica, que podríamos denominar como el de una "textualidad pluriforme", es acentuada por la fragmentariedad y parece tener su justificación en el propio texto:

Lo que me interesa poner de relieve es la infinita variación textual: la lucha entre lucidez e irracionalidad [...] la tensión entre la palabra y la actuación: la falta de ley en un mundo de leyes.

En cuanto al aspecto formal, me rijo por la misma libertad e independencia. Aparto de mi vía todo lo que sea límite, regla, consigna. Uso los géneros de una manera flexible y según las necesidades de cada caso. (37)

Las implicaciones de la búsqueda por esa "variación textual" permiten comprender el desdibujamiento y transgresión de las convenciones de la autobiografía como género que opera en el texto, entre las que se encuentran, si retomamos la clásica definición de Lejeune, el ser "fundamentalmente una narración [...] la perspectiva debe ser fundamentalmente retrospectiva [...] el tema debe ser fundamentalmente la vida individual" (1994: 51, cursivas del original). El énfasis otorgado por Lejeune a estas características para ser cumplidas por la autobiografía en términos de proporcionalidad dan cabida a posibles desplazamientos que el mismo teórico señaló en su momento: "Se trata de una cuestión de proporción o, más bien, de jerarquía: hay zonas naturales de transición con los otros géneros de la literatura íntima (memorias, diario, ensayo)" (1994: 51). Sin embargo, lo que hace Muñiz-Huberman no solo es trabajar en zonas de transición, sino alterar la jerarquía de estas convenciones, aunque sin soltarlas del todo, porque si bien se cumple el cometido de dibujar "la historia de una personalidad", el texto no es fundamentalmente narrativo o retrospectivo, ni trata con esa proporcionalidad la vida individual, si se piensa en esta como la historia personal más íntima. Cada una de estas características, si bien son partícipes, sobre todo en los primeros fragmentos del libro, terminan siendo desdibujadas por otros tonos y modulaciones discursivas, hasta decantar en un perfil más bien intelectual que, sin embargo, no se deslinda del cometido autobiográfico de un escritor. La autoconfiguración se completa, a modo de la representación del funcionamiento de la mirada del escritor que define el mismo texto, como aquella donde las "pequeñas parcelas de obsesiones se convierten en arquitecturas que crecen. En primas de varia óptica” (44).

Este ejercicio de Muñiz-Huberman, alejado de "todo lo que sea límite, regla, consigna", se completa al considerar que en su producción narrativa opera el movimiento inverso, porque es desde los géneros fundamentalmente ficcionales - para continuar con el juego de las proporcionalidades - que otorga la centralidad a su relato de vida, apenas esbozado en la 
autobiografía. Castillos en la tierra (1995) y Molinos sin viento (2001) conforman lo que la misma escritora ha denominado como dos libros de "seudomemorias", en los que, desde una dinámica propiamente novelesca, una voz omnisciente narra la historia de Alberina, ${ }^{18}$ nombre de la protagonista de ambos títulos, que sintetiza otro tipo de binomio realidad-ficción propuesto por la escritora. Retomo la lectura que Diana Castilleja hace de estas seudomemorias que deja en claro la semejanza autobiográfica, o bien la clave autoficcional:

[...] en sus seudomemorias, Muñiz se (re)construye entrelazando trozos de realidad y de imaginación, la contemplación de fotografías, la remembranza de charlas, de recuerdos vividos o inciertos, propios o ajenos... Que sumados a su condición de mujer, sus exilios y desarraigos (propios, ajenos; antiguos, presentes; políticos, religiosos) y su intelectualidad devienen fragmentos que, ensamblados, conforman el relato de Alberina, quien irá apropiándose del mundo que le rodea en un intento por buscar sus propias marcas [...]. Tanto en Castillos en la tierra (1995) como en Molinos sin viento (2001) Muñiz lleva al lector por un viaje de regreso a la infancia de la narradora. Se intenta aquí de recuperar el pasado, incluidos los lugares vividos (Cuba y México), con imágenes que se dividen entre el recuerdo y la idealización. Entre la realidad y la fantasía. La mirada que reconstruye su narración es una mirada que ve hacia el pasado, en retrospectiva. A partir de la cual irá recuperando pedazos, imágenes, recuerdos... o bien, irá olvidando la realidad para distorsionarla a su antojo. (2015: 26)

La doble operación en el tratamiento del binomio vida-obra/obra-vida que la escritora emplea en su literatura dibuja, a modo de un Jano, sus dos caras. Si sus novelas caben en la categoría asignada de "seudomemorias", bien podría valer para El juego de la escritura el subtítulo de "seudoautobiografía". Ambas, complementarias para la (re)reconstrucción de la identidad, por el vínculo que les une: el juego entre el bios y la grafé, aquel que, dice la autora, "es un volver y revolver mundos internos" (33).

\section{Otras rutas}

Ethel Krauze y Angelina Muñiz-Huberman muestran en sus autobiografías la condición fronteriza inherente al género que se planteó al inicio de este trabajo. Desde condiciones de vida comunes, ambas escritoras revelan la dinámica constructiva de la identidad que guía el gesto de la escritura autobiográfica, en el que la arquitectura textual replica el orden constitutivo del sujeto. En un ejercicio valorativo de la implicación de las siete escritoras participantes de la colección De cuerpo entero, quizá Krauze y Muñiz-Huberman sean en las que este gesto arquitectónico se muestra de forma más evidente. La potencia multiforme de la autobiografía en la pluma de las otras escritoras recorre caminos distintos. A modo de apuntes, en miras a un posible acercamiento futuro, enuncio algunas de las claves que completan el mapa de la escritura autobiográfica a mano de las escritoras en esta colección, que no han podido ser completadas aquí por cuestión de espacio. Aline Pettersson recupera la estructura mental de la memoria en una dinámica donde la elisión es el denominador común en la dupla memoria-escritura. María Luisa Mendoza, por su parte, instaura el movimiento de regreso-evolución en la dinámica del género

\footnotetext{
${ }^{18}$ El nombre ficticio de la protagonista es resultado de la fusión de los nombres del esposo de la autora, Alberto, y el nombre de la escritora, Angelina.
} 
con la puesta en juego de una suerte de retorno a los orígenes retóricos y al ágora clásica donde el espacio público se entreteje con el espacio íntimo. Brianda Domecq, con una prosa ágil y fresca, retoma la figura del pícaro, en un claro guiño con una de las modalidades clásicas del estilo autobiográfico, adaptado a la condición femenina y a la dinámica cultural del siglo XX. María Luisa Puga crea el vínculo con la propuesta de Virginia Woolf, como ícono para la escritura íntima escrita por mujeres, con la implicación del sentido de encuentro del "cuarto propio", como una búsqueda que se teje a modo de un itinerario de viaje. Mientras que Beatriz Espejo recurre al relato de infancia como estructura total configuradora de la identidad.

Todas ellas en su conjunto manifiestan la potencia multiforme de la autobiografía por virtud de su naturaleza fronteriza que, como hemos visto, no remite solo al binomio verdad/ficción, sino a la cualidad proteica de la creación literaria. Sobre esta queda aún mucho que decir en su implicación para el caso de la tradición mexicana. Quedan, por ejemplo, los más de veinte títulos restantes de la colección De cuerpo entero, así como la antología Trazos en el espejo. 15 autorretratos fugaces (2011), ${ }^{19}$ la cual bebe también de la línea inaugurada por Carballo y Siles en la dinámica editorial, al reunir ahora a quince escritores de la última generación en las letras mexicanas alrededor de la escritura autobiográfica. Valgan estas breves notas como una invitación para dar continuidad al estudio y análisis de la vida de este género que, en México, requiere aún de un tratamiento sistemático que enuncie y de forma a sus particularidades.

\section{Bibliografía}

CARBALLO, Emmanuel (2015): Diario Público (1966-1968). México: Consejo Nacional para la Cultura y las Artes.

CASTILLEJA, Diana: “Angelina Muñiz-Huberman: construcción de un «yo» fragmentado". Anales de literatura hispanoamericana 44 (2015): 21-33. DOI: https://doi.org/10.5209/rev_alhi.2015.v44.51503

CORTINA, Guadalupe: "Historias y mujeres: feminización de espacios culturales en la narrativa de Ethel Krauze". Texto crítico 10 (enero-junio 2002): 89-106.

ESTRADA, Josefina: "Entrevista a Silvia Molina: el miedo a la literatura". Blog de Silvia Molina:

http://www.silviamolina.com/index.php?option=com content\&view=article\&id=249:estradajosefina-el-miedo-a-la-lit-entrevista\&catid=46:entrevistas\&Itemid=69 (última consulta: 27/10/2017) Texto publicado en Sábado 863 (16 de abril de 1994).

GOLDSMIT BRINDIS, Shulamit: "Judeo-mexicanos: gestación de una identidad". Historia y grafía 35 (julio-diciembre 2010): 93-125.

\footnotetext{
${ }^{19}$ La antología reúne a los escritores Julián Herbert, Guadalupe Nettel, Luis Felipe Fabre, María Rivera, Alberto Chimal, Hernán Bravo Varela, Socorro Venegas, José Ramón Ruiz Sánchez, Brenda Lozano, Agustín Goenaga, Juan José Rodríguez, Martín Solares, Antonio Ramos Revillas, Daniela Tarazona y Luis Jorge Boone, pertenecientes a la generación de los "nacidos en los 70".
} 
GUTIÉRREZ PIÑA, Claudia L.: "La precocidad en la autobiografía mexicana: un proyecto editorial. Nuevos escritores mexicanos del siglo XX presentados por sí mismos". La Palabra 20 (2017). DOI: https://doi.org/10.19053/01218530.n30.2017.6962

KRAUZE, Ethel (1990): De cuerpo entero. Entre la cruz y la estrella. México: Universidad Nacional Autónoma de México, Corunda.

LARA ZAVALA, Hernán: "Semblanza de Silvia Molina". Blog de Silvia Molina: http://www.silviamolina.com/index.php?option=com_content $\&$ view=article\&id=250:1ara-zavalaherna-semblanza\&catid=47:y-su-obra\&Itemid=71 (última consulta: 27/10/2017) Texto leído en la entrega del Premio Sor Juana Inés de la Cruz, el 3 de diciembre de 1998.

LEJEUNE, Philippe (1994): El pacto autobiográfico y otros estudios. Madrid: MegazulEndymion.

LÓPEZ GONZÁLEZ, Aralia: “Quebrantos, búsquedas y azares de una pasión nacional (dos décadas de narrativa mexicana: 1970-1980)". Revista Iberoamericana 164-165 (1993): 659-685. DOI: https://doi.org/10.5195/reviberoamer.1993.5178

MAÍZ, Magdalena (1992): (Entre)textos: perfil de la autobiografia moderna mexicana. Tesis de doctorado. Arizona: Arizona State University.

MATEO GAMBARTE, Eduardo (2014): "Las variadas caras del exilio exploradas por Angelina Muñiz-Huberman”. Homenaje a Angelina Muñiz-Hubeman. Eds. Lilian von der Walde M. Y Mariel Reinoso I. México, Destiempos: 26-71.

MENDOZA, María Luisa (1991): De cuerpo entero. Menguas y contrafuertes. México: Universidad Nacional Autónoma de México, Corunda.

MINARDI, Giovanna: "Encuentro con ocho escritoras mexicanas". Hispamérica 68 (agosto 1994): 61-71.

MOLINA, Silvia (1998): Encuentros y reflexiones. México: Universidad Nacional Autónoma de México.

MOLLOY, Sylvia (1996): Acto de presencia. La escritura autobiográfica en Hispanoamérica. México: El Colegio de México, Fondo de Cultura Económica.

MUÑIZ-HUBERMAN, Angelina (1972): Morada interior. México: Joaquín Mortiz.

--- (1991): De cuerpo entero. El juego de la escritura. México: Universidad Nacional Autónoma de México, Corunda.

PACHECO OROPEZA, Bettina (2007): "La autobiografía del escritor latinoamericano contemporáneo o la revelación de una individualidad diferente en el continente". Actas del XV Congreso de la Asociación Internacional de Hispanistas. Las dos orillas. Eds. Beatriz Mariscal y María Teresa Miaja. México, Fondo de Cultura Económica, Asociación Internacional de Hispanistas, Tecnológico de Monterrey, El Colegio de México: 531-537.

POZUELO YVANCOS, José María (2006): De la autobiografía: teoría y estilos. Barcelona: Crítica.

RAMOS, Raymundo (1967): Memorias y autobiografias de escritores mexicanos. México: Universidad Nacional Autónoma de México. 
REISZ, Susana: "Hipótesis sobre el tema. Escritura femenina e hispanidad". Tropelías 1 (1990): 199-213.

RUFFINELLI, Jorge: “Al margen de la ficción: Autobiografía y literatura mexicana”. Hispania 3 (septiembre 1986): 512-520. DOI: https://doi.org/10.2307/342731

VIVEROS, Luz América (2015): El surgimiento del espacio autobiográfico en México. Impresiones y recuerdos (1893), de Federico Gamboa. México, Universidad Nacional Autónoma de México, Instituto de Investigaciones Filológicas, Seminario de Edición Crítica de Textos.

WOODS, Richard D. (1988): Mexican Autobiography / La autobiografía mexicana. An Annotated Bibliography / Una bibliografía razonada. Connecticut: Greenwood.

---: "Mexican Autobiography: An Essay and Annotated Bibliography". Hispania 4 (diciembre 1994): 750-802.

---: “Profile of Women's Autobiography in México". Letras femeninas 1-2 (primavera-otoño 1994): 9-22.

C) Claudia L. Gutiérrez Piña

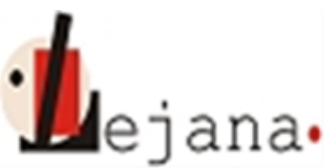

http://ojs.elte.hu/index.php/lejana

Universidad Eötvös Loránd, Departamento de Español, 1088 Budapest, Múzeum krt. 4/C 